\title{
A MUTAÇÃO CONSTITUCIONAL COMO INSTRUMENTO DO STF PARA ATUAR COMO LEGISLADOR POSITIVO: A necessidade de um controle externo às modificações constitucionais realizadas por meio da interpretação
}

\author{
CONSTITUTIONAL MUTATION AS AN INSTRUMENT OF STF TO ACT AS \\ POSITIVE LEGISLATOR: The need for an external control to the \\ constitutional changes made by means of interpretation
}

Alexandre de Castro Nogueira ${ }^{1}$

SUMÁRIO: Introdução; 1 . As Constituições e o Fenômeno da Mutação Constitucional; 2. A Mutação Constitucional nas Decisõesd do STF; 3. A Necessidade de Controle Sobre as Modificações Constitucionais Difusas Ilegítimas; Considerações Finais; Referências das Fontes Citadas;

\section{RESUMO}

O presente artigo visa identificar os principais julgados do STF que tenham fundamentação que apresente ou demonstre a aplicação (inoportuna) da mutação constitucional, modificando não o sentido, mas o texto do dispositivo constitucional interpretado, pondo-se na posição de legislador positivo, visando propor uma solução legítima dentro do ordenamento jurídico pátrio.

PALAVRAS-CHAVE: Mutação Constitucional; STF; Poder Legislativo.

\section{ABSTRACT}

The present Paper aims to identify the mostly judgments in the Brazilian Supreme Court and the reasons that have to present or demonstrate the application (untimely) constitutional mutation, does not alter the meaning, but the text of the constitutional provision interpreted, putting yourself in a positive

\footnotetext{
${ }^{1}$ Doutorando em Direito Público pela UNISINOS. Advogado.
} 
NOGUEIRA, Alexandre de Castro. A mutação constitucional como instrumento do stf para atuar como legislador positivo: a necessidade de um controle externo às modificações constitucionais realizadas por meio da interpretação. Revista Eletrônica Direito e Política, Programa de PósGraduação Stricto Sensu em Ciência Jurídica da UNIVALI, Itajaí, v.10, n.4, 30 quadrimestre de 2015. Disponível em: www.univali.br/direitoepolitica - ISSN 1980-7791.

position legislature, aiming to propose a legitimate solution within the national legal system.

KEYWORD: Constitutional mutation; STF; Legislature.

\section{INTRODUÇÃO}

A Constituição como norma maior de regulamentação do Direito posto deve acompanhar a evolução social, não podendo ignorar avanços realizados no contexto em que ela está inserida, sob a pena de gerar uma crise de legitimidade. No entanto, tem ela a força normativa para se impuser e influir esta mesma realidade, agindo em coordenação com a mesma.

No entanto, o STF vem adotando posições que podem ser consideradas verdadeiros excessos na atualização dos sentidos da Constituição Federal pátria, agindo tal qual um legislador positivo, usando o fenômeno conhecido como mutação constitucional como um pretexto ou até mesmo álibi para a indevida modificação, acrescentando palavras, ao texto da constituição, conforme os precedentes que se apresentará neste trabalho.

\section{AS CONSTITUIÇÕES E O FENÔMENO DA MUTAÇÃO CONSTITUCIONAL}

As Constituições, compreendidas como textos jurídicos dotados de normatividade ${ }^{2}$ estando na base, no topo do Ordenamento Jurídico na qual estão inseridas $^{3}$, para manter a sua força necessitam de uma segurança, proteção contra a vontade do legislador ordinário, ou seja, devem ser rígidas, compreendidas assim aquelas constituições que possuem um processo

\footnotetext{
${ }^{2}$ HESSE, Konrad. A força normativa da Constituição. Tradução de Gilmar Ferreira Mendes. Porto Alegre: Sergio Antônio Fabris Editor, 1991, p 16.

${ }^{3}$ KELSEN, Hans. Teoria pura do Direito. Tradução de João Baptista Machado. 8a Ed. São Paulo: Martins Fontes, 2008, p. 142.
} 
NOGUEIRA, Alexandre de Castro. A mutação constitucional como instrumento do stf para atuar como legislador positivo: a necessidade de um controle externo às modificações constitucionais realizadas por meio da interpretação. Revista Eletrônica Direito e Política, Programa de PósGraduação Stricto Sensu em Ciência Jurídica da UNIVALI, Itajaí, v.10, n.4, 30 quadrimestre de 2015. Disponível em: www.univali.br/direitoepolitica - ISSN 1980-7791.

modificativo diferenciado, mais difícil e mais exigente, em comparação com o processo de criação e modificação das legislações infraconstitucionais.

Inobstante, as Constituições não podem ser colocadas de tal forma que seja impossível a sua alteração, posto que se trata de um processo evolutivo necessário para a sua adequação à realidade social contemporânea, ou no dizer de Barroso 4 , "uma geração não pode submeter à outra os seus desígnios".

Por isso reconhece-se a possibilidade de modificação constitucional, seja através de emendas, de atos constitucionais legislativos dotados de força modificativa, considerados meios expressos ou formais, seja através de processos informais ou tácitos. Entre os processos tácitos de modificação constitucional está a mutação constitucional, que, com esforço, pode ser comparada à uma espécie de interpretação evolutiva ${ }^{5}$.

Assim, a mutação constitucional seria um "mecanismo que permite a transformação do sentido e do alcance de normas da Constituição, sem que se opere, no entanto, qualquer modificação de seu texto." ${ }^{6}$.

Hesse $^{7}$ defende a rigidez e a mobilidade das constituições, entendendo que devem ser capaz de sofrer as transformações em decorrência de mudanças inevitáveis, afirmando que "uma mudança das relações fáticas pode, ou deve, provocar mudanças na interpretação da Constituição" ${ }^{8}$.

4 BARROSO, Luís Roberto. Curso de direito constitucional contemporâneo: os conceitos fundamentais e a construção do novo modelo. São Paulo: Saraiva, 2011, p. 145.

5 MIRANDA, Jorge. Manual de Direito Constitucional. 6a Ed. 2a ed. Coimbra: Coimbra Editoral, 2007, p. 159.

6 BARROSO, Luís Roberto. Curso de direito constitucional contemporâneo: os conceitos fundamentais e a construção do novo modelo, p. 146.

7 HESSE, Konrad. Elementos de Direito Constitucional da República Federal da Alemanha. Tradução de Luís Afonso Heck. Porto Alegre: Sergio Antonio Fabris Editor, 1998, p. 12.

8 HESSE, Konrad. A força normativa da Constituição, p. 23. 
NOGUEIRA, Alexandre de Castro. A mutação constitucional como instrumento do stf para atuar como legislador positivo: a necessidade de um controle externo às modificações constitucionais realizadas por meio da interpretação. Revista Eletrônica Direito e Política, Programa de PósGraduação Stricto Sensu em Ciência Jurídica da UNIVALI, Itajaí, v.10, n.4, 30 quadrimestre de 2015. Disponível em: www.univali.br/direitoepolitica - ISSN 1980-7791.

Em pertinente crítica a esse fenômeno, Streck, Oliveira e Lima ${ }^{9}$, reconhecendo o protagonismo judicial nessa espécie de alteração constitucional, apresenta:

Em síntese, a tese da mutação constitucional 'advoga em última análise uma concepção decisionista da jurisdição e contribui para a compreensão das cortes constitucionais como poderes constituintes permanentes.' Ora, um tribunal não pode mudar a constituição; um tribunal não pode "inventar" o direito: este não é seu legítimo papel como poder jurisdicional, numa democracia.

O mesmo autor alerta que:

$\mathrm{Na}$ verdade, o conceito de mutação constitucional mostra apenas a incapacidade do positivismo legalista da velha Staatsrechtslehre do Reich alemão de 1870 em lidar construtivamente com a profundidade de sua própria crise paradigmática. E não nos parece que esse fenômeno possui similaridade no Brasil. ${ }^{\prime 10}$.

É importante notar, também, que Hesse ${ }^{11}$, ao defender a mobilidade do sentido do texto constitucional, também defende a sua rigidez, afirmando que "ao mesmo tempo, o sentido da proposição jurídica estabelece o limite da interpretação e, por conseguinte, o limite de qualquer mutação normativa. ${ }^{\prime 12}$.

\section{A MUTAÇÃO CONSTITUCIONAL NAS DECISÕES DO STF}

A mutação constitucional tem sido utilizada pela Corte Suprema sem os devidos cuidados e desrespeitando os limites da própria normatividade da constituição ${ }^{13}$,

\footnotetext{
${ }^{9}$ STRECK, Lenio Luiz; OLIVEIRA, Marcelo Andrade Cattoni de et al. A nova perspectiva do Supremo Tribunal Federal sobre o controle difuso: mutação constitucional e limites da legitimidade da jurisdição constitucional. Jus Navigandi, Teresina, ano 12, n. 1498, 8 ago. 2007. Disponível em: <http://jus.com.br/artigos/10253>. Acesso em: 25 abr. 2014. , p. 21

10 STRECK, Lenio Luiz; OLIVEIRA, Marcelo Andrade Cattoni de et al. A nova perspectiva do Supremo Tribunal Federal sobre o controle difuso: mutação constitucional e limites da legitimidade da jurisdição constitucional, p. 20.

11 HESSE, Konrad. A força normativa da Constituição, p. 24.

12 HESSE, Konrad. A força normativa da Constituição, p. 23.

${ }^{13}$ HESSE, Konrad. A força normativa da Constituição, p. 24.
} 
NOGUEIRA, Alexandre de Castro. A mutação constitucional como instrumento do stf para atuar como legislador positivo: a necessidade de um controle externo às modificações constitucionais realizadas por meio da interpretação. Revista Eletrônica Direito e Política, Programa de PósGraduação Stricto Sensu em Ciência Jurídica da UNIVALI, Itajaí, v.10, n.4, $3^{\circ}$ quadrimestre de 2015. Disponível em: www.univali.br/direitoepolitica - ISSN 1980-7791.

impondo ou tentando expor, uma força legiferante positiva, disfarçada, dissimulada, de interpretação evolutiva, ou mutação constitucional, como pode se notar através na análise que se inicia a seguir.

2.1 Competência da justiça do trabalho para as ações acidentárias - RE $450504^{14}$.

A Constituição Federal prevê, expressamente, a competência do STF (art. 102), STJ (art. 105), TRF (art. 108) e da Justiça Federal (art. 109), assim como a competência da Justiça do Trabalho (art. 114), deixado a cargo da legislação infraconstitucional a definição da competência dos demais órgãos jurisdicionais ${ }^{15}$.

É certo que, e sem a necessidade de maiores debates, as competências constitucionais expressas são exclusivas e limitadas, tratando-se de verdadeiros numerus clausus.

O art. 114 da CF/88, que define a competência da Justiça do Trabalho, após a redação que Ihe deu a E.C. 45/2004, assim se apresenta:

Art. 114. Compete à Justiça do Trabalho processar e julgar:

I as ações oriundas da relação de trabalho, abrangidos os entes de direito público externo e da administração pública direta e indireta da União, dos Estados, do Distrito Federal e dos Municípios;

II as ações que envolvam exercício do direito de greve;

III as ações sobre representação sindical, entre sindicatos, entre sindicatos e trabalhadores, e entre sindicatos e empregadores;

IV os mandados de segurança, habeas corpus e habeas data , quando o ato questionado envolver matéria sujeita à sua jurisdição;

${ }^{14}$ Relator(a): Min. CARLOS BRITTO, Primeira Turma, julgado em 21/11/2006, DJ 02-02-2007 PP00116 EMENT VOL-02262-09 PP-01836

${ }^{15}$ A exemplo do que ocorre com a Justiça Eleitoral, conforme o art. 121 da C.F. 
NOGUEIRA, Alexandre de Castro. A mutação constitucional como instrumento do stf para atuar como legislador positivo: a necessidade de um controle externo às modificações constitucionais realizadas por meio da interpretação. Revista Eletrônica Direito e Política, Programa de PósGraduação Stricto Sensu em Ciência Jurídica da UNIVALI, Itajaí, v.10, n.4, 30 quadrimestre de 2015. Disponível em: www.univali.br/direitoepolitica - ISSN 1980-7791.

V os conflitos de competência entre órgãos com jurisdição trabalhista, ressalvado o disposto no art. 102, I, o;

VI as ações de indenização por dano moral ou patrimonial, decorrentes da relação de trabalho;

VII as ações relativas às penalidades administrativas impostas aos empregadores pelos órgãos de fiscalização das relações de trabalho; VIII a execução, de ofício, das contribuições sociais previstas no art. 195, I, a, e II, e seus acréscimos legais, decorrentes das sentenças que proferir;

IX outras controvérsias decorrentes da relação de trabalho, na forma da lei.

O STF, no entanto, reconheceu a competência da Justiça do Trabalho para as causas relativas à indenização de ações acidentárias decorrentes de acidente de trabalho, antes da competência da justiça comum, mas o fez, conforme o voto do relator, por verificar mutação constitucional, que teve como marco temporal a E.C. no 45/2004, conforme se nota na ementa que se segue:

EMENTA: AGRAVO REGIMENTAL EM RECURSO EXTRAORDINÁRIO. CONSTITUCIONAL. COMPETÊNCIA EM RAZÃO DA MATÉRIA. AÇÃO DE INDENIZAÇÃO POR ACIDENTE DE TRABALHO, PROPOSTA CONTRA O (EX)EMPREGADOR. COMPETÊNCIA DA JUSTIÇA ESPECIAL. AÇÕES EM TRÂMITE NA JUSTIÇA COMUM DOS ESTADOS ANTES DA EC NO 45/04. PRORROGAÇÃO DA COMPETÊNCIA, SE JÁ APRECIADO O MÉRITO DO PEDIDO. DIREITO ADQUIRIDO PROCESSUAL. Compete à Justiça do Trabalho apreciar e julgar pedido de indenização por acidente de trabalho, deduzido contra o (ex)empregador, nos termos da redação originária do artigo 114 c/c inciso I do artigo 109 da Lei Maior. As ações em trâmite na Justiça comum estadual e com sentença de mérito anterior à promulgação da EC 45/04 lá continuam até o trânsito em julgado e correspondente execução. [...]. Precedente plenário: CC 7.204. Outros precedentes: RE 461.925-AgR, RE 485.636-AgR, RE 486.966-AgR e RE 502.342-Ag. Agravo regimental desprovido. 
NOGUEIRA, Alexandre de Castro. A mutação constitucional como instrumento do stf para atuar como legislador positivo: a necessidade de um controle externo às modificações constitucionais realizadas por meio da interpretação. Revista Eletrônica Direito e Política, Programa de PósGraduação Stricto Sensu em Ciência Jurídica da UNIVALI, Itajaí, v.10, n.4, 30 quadrimestre de 2015. Disponível em: www.univali.br/direitoepolitica - ISSN 1980-7791.

Neste caso o STF, embora seja expressa e limitada a competência da Justiça do Trabalho no texto constitucional, evoluiu seu entendimento, para acrescentar mais uma matéria na competência da citada justiça especializada.

Apesar do STF ter informado o reconhecimento da mutação constitucional, não apresentou maiores esclarecimentos sobre a ocorrência do referido fenômeno julgado.

\subsection{0 caso da infidelidade partidária - MS $26603^{16}$}

Neste caso, cujo objeto é analise da questão da (in) fidelidade partidária, mais importante do que a conclusão em si sobre a matéria, é o entendimento do STF sobre a sua própria competência de guardião da Constituição e de como entende o instituto da mutação constitucional conforme se observa o julgado abaixo:

E M E N T A: MANDADO DE SEGURANÇA - QUESTÕES PRELIMINARES REJEITADAS - O MANDADO DE SEGURANÇA COMO PROCESSO DOCUMENTAL E A NOÇÃO DE DIREITO LÍQUIDO E CERTO - NECESSIDADE DE PROVA PRÉCONSTITUÍDA - A COMPREENSÃO DO CONCEITO DE AUTORIDADE COATORA, PARA FINS MANDAMENTAIS RESERVA ESTATUTÁRIA, DIREITO AO PROCESSO E EXERCÍCIO DA JURISDIÇÃO - INOPONIBILIDADE, AO PODER JUDICIÁRIO, DA RESERVA DE ESTATUTO, QUANDO INSTAURADO LITÍGIO CONSTITUCIONAL EM TORNO DE ATOS PARTIDÁRIOS "INTERNA CORPORIS" - COMPETÊNCIA NORMATIVA DO TRIBUNAL SUPERIOR ELEITORAL - O INSTITUTO DA "CONSULTA" NO ÂMBITO DA JUSTIÇA ELEITORAL: NATUREZA E EFEITOS JURÍDICOS POSSIBILIDADE DE O TRIBUNAL SUPERIOR ELEITORAL, EM RESPOSTA À CONSULTA, NELA EXAMINAR TESE JURÍDICA EM FACE DA CONSTITUIÇÃO DA REPÚBLICA CONSULTA/TSE N 1.398/DF - FIDELIDADE PARTIDÁRIA - A ESSENCIALIDADE DOS PARTIDOS POLÍTICOS NO PROCESSO DE PODER - MANDATO ELETIVO - VÍNCULO PARTIDÁRIO E VÍNCULO POPULAR - INFIDELIDADE PARTIDÁRIA - CAUSA GERADORA DO DIREITO DE A AGREMIAÇÃO PARTIDÁRIA PREJUDICADA PRESERVAR A VAGA OBTIDA PELO SISTEMA PROPORCIONAL $[\ldots]$

16 Relator(a): Min. CELSO DE MELLO, Tribunal Pleno, julgado em 04/10/2007, DJe-241 DIVULG 18-12-2008 PUBLIC 19-12-2008 EMENT VOL-02346-02 PP-00318 
NOGUEIRA, Alexandre de Castro. A mutação constitucional como instrumento do stf para atuar como legislador positivo: a necessidade de um controle externo às modificações constitucionais realizadas por meio da interpretação. Revista Eletrônica Direito e Política, Programa de PósGraduação Stricto Sensu em Ciência Jurídica da UNIVALI, Itajaí, v.10, n.4, 30 quadrimestre de 2015. Disponível em: www.univali.br/direitoepolitica - ISSN 1980-7791.

A FORÇA NORMATIVA DA CONSTITUIÇÃO E O MONOPÓLIO DA ÚLTIMA PALAVRA, PELO SUPREMO TRIBUNAL FEDERAL, EM MATÉRIA DE INTERPRETAÇÃO CONSTITUCIONAL. - O exercício da jurisdição constitucional, que tem por objetivo preservar a supremacia da Constituição, põe em evidência a dimensão essencialmente política em que se projeta a atividade institucional do Supremo Tribunal Federal, pois, no processo de indagação constitucional, assenta-se a magna prerrogativa de decidir, em última análise, sobre a própria substância do poder. - No poder de interpretar a Lei Fundamental, reside a prerrogativa extraordinária de (re)formulá-la, eis que a interpretação judicial achase compreendida entre os processos informais de mutação constitucional, a significar, portanto, que "A Constituição está em elaboração permanente nos Tribunais incumbidos de aplicá-la". Doutrina. Precedentes. - A interpretação constitucional derivada das decisões proferidas pelo Supremo Tribunal Federal - a quem se atribuiu a função eminente de "guarda da Constituição" (CF, art. 102, "caput") - assume papel de fundamental importância na organização institucional do Estado brasileiro, a justificar o reconhecimento de que o modelo político-jurídico vigente em nosso País conferiu, à Suprema Corte, a singular prerrogativa de dispor do monopólio da última palavra em tema de exegese das normas inscritas no texto da Lei Fundamental. (G. N.)

O trecho em destaque demonstra a visão solipsista e voluntarista da Suprema Corte, que the auto-concede o poder de "(re)formular" a constituição, vale o destaque a essa expressão posto que tanto se pode ler "reformular", no sentido de rever, como formular, no sentido de criar, que é competência do poder constituinte e não do Judiciário.

Mais uma vez o STF não apresentou maiores esclarecimentos sobre a ocorrência do fenômeno da mutação constitucional. 
NOGUEIRA, Alexandre de Castro. A mutação constitucional como instrumento do stf para atuar como legislador positivo: a necessidade de um controle externo às modificações constitucionais realizadas por meio da interpretação. Revista Eletrônica Direito e Política, Programa de PósGraduação Stricto Sensu em Ciência Jurídica da UNIVALI, Itajaí, v.10, n.4, 30 quadrimestre de 2015. Disponível em: www.univali.br/direitoepolitica - ISSN 1980-7791.

\subsection{A revogação da prisão civil do depositário infiel $-\mathrm{HC} 96772^{17}$}

A CF/88 previu somente duas possibilidades de prisão por dívida, a decorrente de pensão alimentícia e a prisão do depositário infiel, conforme expressa redação do art. 50, LXVII, mas em razão da Convenção de Direito Humanos, que somente permitia a prisão do devedor de pensão alimentícia, o STF reconheceu a "ilegitimidade jurídica" da prisão do depositário infiel em decorrência de mutação constitucional, conforme exceto da ementa que se segue:

E M E N T A: "HABEAS CORPUS" - PRISÃO CIVIL DEPOSITÁRIO JUDICIAL - REVOGAÇÃO DA SÚMULA 619/STF - A QUESTÃO DA INFIDELIDADE DEPOSITÁRIA CONVENÇÃO AMERICANA DE DIREITOS HUMANOS (ARTIGO 70, n. 7) - NATUREZA CONSTITUCIONAL OU CARATER DE SUPRALEGALIDADE DOS TRATADOS INTERNACIONAIS DE DIREITOS HUMANOS? - PEDIDO DEFERIDO. ILEGITIMIDADE JURÍDICA DA DECRETAÇÃO DA PRISÃO CIVIL DO DEPOSITÁRIO INFIEL, AINDA QUE SE CUIDE DE DEPOSITÁRIO JUDICIAL. - Não mais subsiste, no sistema normativo brasileiro, a prisão civil por infidelidade depositária, independentemente da modalidade de depósito, trate-se de depósito voluntário (convencional) ou cuide-se de depósito necessário, como o é o depósito judicial. Precedentes. Revogação da Súmula 619/STF. TRATADOS INTERNACIONAIS DE DIREITOS HUMANOS: AS SUAS RELAÇÕES COM O DIREITO INTERNO BRASILEIRO E A QUESTÃO DE SUA POSIÇÃO HIERÁRQUICA. - A Convenção Americana sobre Direitos Humanos (Art. 70, n. 7). Caráter subordinante dos tratados internacionais em matéria de direitos humanos e o sistema de proteção dos direitos básicos da pessoa humana. - Relações entre o direito interno brasileiro e as convenções internacionais de direitos humanos (CF, art. $5^{\circ}$ e $\S \S 2^{\circ}$ e $3^{\circ}$ ). Precedentes. - Posição hierárquica dos tratados internacionais de direitos humanos no ordenamento positivo interno do Brasil: natureza constitucional ou caráter de supralegalidade? - Entendimento do Relator, Min. CELSO DE MELLO, que atribui hierarquia constitucional às convenções internacionais em matéria de direitos humanos. A INTERPRETAÇÃO JUDICIAL COMO INSTRUMENTO DE MUTAÇÃO INFORMAL DA

\footnotetext{
17 Relator(a): Min. CELSO DE MELLO, Segunda Turma, julgado em 09/06/2009, DJe-157 DIVULG 20-08-2009 PUBLIC 21-08-2009 EMENT VOL-02370-04 PP-00811 RTJ VOL-00218- PP-00327 RT v. 98, n. 889,2009 , p. $173-183$
} 
NOGUEIRA, Alexandre de Castro. A mutação constitucional como instrumento do stf para atuar como legislador positivo: a necessidade de um controle externo às modificações constitucionais realizadas por meio da interpretação. Revista Eletrônica Direito e Política, Programa de PósGraduação Stricto Sensu em Ciência Jurídica da UNIVALI, Itajaí, v.10, n.4, 30 quadrimestre de 2015. Disponível em: www.univali.br/direitoepolitica - ISSN 1980-7791.

CONSTITUIÇÃo. - A questão dos processos informais de mutação constitucional e o papel do Poder Judiciário: a interpretação judicial como instrumento juridicamente idôneo de mudança informal da Constituição. A legitimidade da adequação, mediante interpretação do Poder Judiciário, da própria Constituição da República, se e quando imperioso compatibilizá-la, mediante exegese atualizadora, com as novas exigências, necessidades e transformações resultantes dos processos sociais, econômicos e políticos que caracterizam, em seus múltiplos e complexos aspectos, a sociedade contemporânea. [...].

Interessante notar que, com a novel redação do art. $5^{\circ}, \S 2^{\circ}$, C.F., os tratados e convenções de direitos humanos que forem recepcionados pelo mesmo procedimento das emendas constitucionais (quorum de $3 / 5 \mathrm{com}$ duplo turno de votação em ambas as casas), possuirão status de norma constitucional.

Mas tal procedimento não ocorreu com a Convenção Americana de Direitos Humanos, o que a coloca na condição de norma infraconstitucional, não podendo revogar texto da Carta Magna.

No entanto, o STF, para prestigiar seu posicionamento, aumentar o seu Poder perante o Sistema Constitucional achou por bem reconhecer mutação constitucional da norma do art. 50, LXVII, para suprimir, ou melhor, revogar, a previsão de prisão civil do depositário infiel. Expediu, inclusive, a Súmula Vinculante no 25, para garantir a vinculação de seu entendimento.

Novamente o STF não apresentou maiores esclarecimentos sobre a ocorrência do fenômeno da mutação constitucional, impondo seu posicionamento perante o sistema jurídico. 
NOGUEIRA, Alexandre de Castro. A mutação constitucional como instrumento do stf para atuar como legislador positivo: a necessidade de um controle externo às modificações constitucionais realizadas por meio da interpretação. Revista Eletrônica Direito e Política, Programa de PósGraduação Stricto Sensu em Ciência Jurídica da UNIVALI, Itajaí, v.10, n.4, 30 quadrimestre de 2015. Disponível em: www.univali.br/direitoepolitica - ISSN 1980-7791.

\subsection{A UNIÃO HOMOAFETIVA - ADI $4277^{18}$ :}

O STF, no julgamento da ADI 4277 e ADPF 132, embora não demonstre expressamente, a pretexto de uma interpretação conforme a constituição do art. 1.723 do Código Civil, que atendia, em essência, o disposto no art. 226, §20 da Constituição Federal, modificou, por instrumento difuso de alteração constitucional, esse dispositivo da Carta Magna e incluiu no conceito de família, mormente quanto à união estável, algo além do que o Constituinte de 1988 disse, conforme excerto de ementa que se segue:

ARGUIÇÃO DE DESCUMPRIMENTO DE PRECEITO FUNDAMENTAL (ADPF). PERDA PARCIAL DE OBJETO. RECEBIMENTO, NA PARTE REMANESCENTE, COMO AÇÃO DIRETA DE INCONSTITUCIONALIDADE. UNIÃO HOMOAFETIVA E SEU RECONHECIMENTO COMO INSTITUTO JURÍDICO. CONVERGÊNCIA DE OBJETOS ENTRE AÇÕES DE NATUREZA ABSTRATA. JULGAMENTO CONJUNTO. Encampação dos fundamentos da ADPF no 132-RJ pela ADI no 4.277-DF, com a finalidade de conferir "interpretação conforme à Constituição" ao art. 1.723 do Código Civil. Atendimento das condições da ação. 2. PROIBIÇÃO DE DISCRIMINAÇÃO DAS PESSOAS EM RAZÃO DO SEXO, SEJA NO PLANO DA DICOTOMIA HOMEM/MULHER (GÊNERO), SEJA NO PLANO DA ORIENTAÇÃO SEXUAL DE CADA QUAL DELES. A PROIBIÇÃO DO PRECONCEITO COMO CAPÍTULO DO CONSTITUCIONALISMO FRATERNAL. HOMENAGEM AO PLURALISMO COMO VALOR SÓCIO-POLÍTICO-CULTURAL. LIBERDADE PARA DISPOR DA PRÓPRIA SEXUALIDADE, INSERIDA NA CATEGORIA DOS DIREITOS FUNDAMENTAIS DO INDIVÍDUO, EXPRESSÃO QUE É DA AUTONOMIA DE VONTADE. DIREITO À INTIMIDADE E À VIDA PRIVADA. CLÁUSULA PÉTREA.
(...)
3.
TRATAMENTO

CONSTITUCIONAL DA INSTITUIÇÃO DA FAMÍLIA. RECONHECIMENTO DE QUE A CONSTITUIÇÃO FEDERAL NÃO EMPRESTA AO SUBSTANTIVO "FAMÍLIA" NENHUM SIGNIFICADO ORTODOXO OU DA PRÓPRIA TÉCNICA JURÍDICA. A FAMÍLIA COMO CATEGORIA SÓCIO-CULTURAL E PRINCÍPIO ESPIRITUAL. DIREITO SUBJETIVO DE CONSTITUIR FAMÍLIA.

\footnotetext{
18 ADI 4277, Relator(a): Min. AYRES BRITTO, Tribunal Pleno, julgado em 05/05/2011, DJe-198 DIVULG 13-10-2011 PUBLIC 14-10-2011 EMENT VOL-02607-03 PP-00341 RTJ VOL-00219- PP00212
} 
NOGUEIRA, Alexandre de Castro. A mutação constitucional como instrumento do stf para atuar como legislador positivo: a necessidade de um controle externo às modificações constitucionais realizadas por meio da interpretação. Revista Eletrônica Direito e Política, Programa de PósGraduação Stricto Sensu em Ciência Jurídica da UNIVALI, Itajaí, v.10, n.4, 30 quadrimestre de 2015. Disponível em: www.univali.br/direitoepolitica - ISSN 1980-7791.

INTERPRETAÇÃO NÃO-REDUCIONISTA. (...). 4. UNIÃO ESTÁVEL. NORMAÇÃO CONSTITUCIONAL REFERIDA A HOMEM E MULHER, MAS APENAS PARA ESPECIAL PROTEÇÃO DESTA ÚLTIMA. FOCADO PROPÓSITO CONSTITUCIONAL DE ESTABELECER RELAÇÕES JURÍDICAS HORIZONTAIS OU SEM HIERARQUIA ENTRE AS DUAS TIPOLOGIAS DO GÊNERO HUMANO. IDENTIDADE CONSTITUCIONAL DOS CONCEITOS DE "ENTIDADE FAMILIAR" E "FAMÍLIA". (...). 6. INTERPRETAÇÃO DO ART. 1.723 DO CÓDIGO CIVIL EM CONFORMIDADE COM A CONSTITUIÇÃO FEDERAL (TÉCNICA DA "INTERPRETAÇÃO CONFORME"). RECONHECIMENTO DA UNIÃO HOMOAFETIVA COMO FAMÍLIA. PROCEDÊNCIA DAS AÇões. Ante a possibilidade de interpretação em sentido preconceituoso ou discriminatório do art. 1.723 do Código Civil, não resolúvel à luz dele próprio, faz-se necessária a utilização da técnica de "interpretação conforme à Constituição". Isso para excluir do dispositivo em causa qualquer significado que impeça o reconhecimento da união contínua, pública e duradoura entre pessoas do mesmo sexo como família. Reconhecimento que é de ser feito segundo as mesmas regras e com as mesmas consequências da união estável heteroafetiva.

É certo que a sociedade evoluiu, e talvez já fosse o momento para a superação de um conceito retrogrado de família, garantindo a proteção legal à união homoafetiva, mas a qual custo, a que preço?

Ignorar o texto constitucional não é a saída. A democracia tem seus defeitos. Embora resguarde o direito das minorias, às vezes essas se encontram sufocadas pela maioria e não encontram o espaço que the é devido. Mas tal situação deve ser resolvida do ponto de vista político, social, através dos representante das minorias nas bancadas legislativas ou de movimentos sociais, mas não pela intervenção do judiciário de forma tão prejudicial ao texto constitucional.

Não é pela situação específica, mas sim pelo precedente que pode custar caro, bastante caro para todo o sistema jurídico de um estado democrático de direito como o do Brasil. 
NOGUEIRA, Alexandre de Castro. A mutação constitucional como instrumento do stf para atuar como legislador positivo: a necessidade de um controle externo às modificações constitucionais realizadas por meio da interpretação. Revista Eletrônica Direito e Política, Programa de PósGraduação Stricto Sensu em Ciência Jurídica da UNIVALI, Itajaí, v.10, n.4, 30 quadrimestre de 2015. Disponível em: www.univali.br/direitoepolitica - ISSN 1980-7791.

Com razão, em parte, o Ministro Ricardo Lewandowski, que entendeu não ser possível a aplicação da mutação constitucional ou mesmo de se fazer uma interpretação extensiva dos dispositivos constitucionais citados na ação, por conta dos limites materiais e formais que a própria Constituição estabeleceu, afirmando que não pode haver aplicação metodológica da integração, fazendo como que o Juiz substitua o legislador.

2.5 A competência do Senado - art. 52, X, CF/88 e a reclamação 4335-AC.

Esta Reclamação talvez tenha sido o pivô de uma das maiores crises institucionais entre o Poder Judiciário e o Legislativo, posto que o STF retira expressa competência do Senado Federal, prevista no art. 52, X da C.F., reduzindo os "poderes" daquela casa legislativa, e aumentado os seus.

O Ministro Gilmar Mendes relator da reclamação 4335-5, afirma que de acordo com a jurisprudência do Supremo Tribunal Federal (Rcl. no 1880, 23.05.2002), o Tribunal reconhece o cabimento de reclamações que comprovem "prejuízo resultante de decisões contrárias às teses do Supremo Tribunal Federal, em reconhecimento à eficácia vinculante erga omnes das decisões de mérito proferidas em sede de controle concentrado".

Ou seja, passa a discutir teses, buscando equiparar os efeitos do controle difuso ao concentrado. Trata-se de uma tese sedutora do ponto de vista da conquista de espaço, Poder, pragmática, mas imagine-se o inverso: o Senado querendo aplicar o art. 52, X, às decisões em controle concentrado.

Assim, trata-se de uma óbvia supressão de competência expressamente prevista. O Min. Eros Grau vai dizer, nessa reclamação, que:

Passamos em verdade de um texto [pelo qual] compete privativamente ao Senado Federal suspender a execução, no todo ou em parte, de lei declarada inconstitucional por decisão definitiva do Supremo Tribunal Federal, a outro texto: "compete privativamente ao Senado Federal dar 
NOGUEIRA, Alexandre de Castro. A mutação constitucional como instrumento do stf para atuar como legislador positivo: a necessidade de um controle externo às modificações constitucionais realizadas por meio da interpretação. Revista Eletrônica Direito e Política, Programa de PósGraduação Stricto Sensu em Ciência Jurídica da UNIVALI, Itajaí, v.10, n.4, 30 quadrimestre de 2015. Disponível em: www.univali.br/direitoepolitica - ISSN 1980-7791.

publicidade à suspensão da execução, operada pelo Supremo Tribunal Federal, de lei declarada inconstitucional, no todo ou em parte, por decisão definitiva do Supremo.

Mas, excluir a competência do Senado Federal - ou conferir-lhe apenas um caráter de tornar público o entendimento do Supremo Tribunal Federal - significa reduzir as atribuições do Senado Federal à de uma secretaria de divulgação intra-legistativa das decisões do Supremo Tribunal Federal; significa, por fim, retirar do processo de controle difuso qualquer possibilidade de chancela dos representantes do povo deste referido processo, o que não parece ser sequer sugerido pela Constituição da República de $1988^{19}$.

Outra questão levantada na obra citada acima é a transformação à revelia dos dispositivos constitucionais, dos efeitos das decisões do controle difuso em concentrado, tratando, sem a participação do Senado, como ordena a Constituição, na concessão de efeitos erga omnes, ao invés do efeito intra partes, podendo ofender o devido processo legal previsto no art. 50, LIV da C.F., e alertam que:

Não estamos em sede de controle concentrado! Tal decisão aqui terá, na verdade, efeitos avocatórios. Eis, portanto, um problema central: a lesão a direitos fundamentais. É preciso entender que a questão do papel do Senado no controle difuso de constitucionalidade diz respeito aos efeitos da decisão. O texto do art. 52, X, da Constituição do Brasil, somente tem sentido se analisado - portanto, a norma que dele se extrai - a partir de uma análise do sistema constitucional brasileiro. O sistema é misto. Por tanto, não se pode inferir que uma decisão em sede de controle tem a mesma eficácia que uma em controle concentrado, devido a diferença destes. $\mathrm{O}$ que está em jogo na presente discussão

\footnotetext{
${ }^{19}$ STRECK, Lenio Luiz; OLIVEIRA, Marcelo Andrade Cattoni de et al. A nova perspectiva do Supremo Tribunal Federal sobre o controle difuso: mutação constitucional e limites da legitimidade da jurisdição constitucional, p. 7.
} 
NOGUEIRA, Alexandre de Castro. A mutação constitucional como instrumento do stf para atuar como legislador positivo: a necessidade de um controle externo às modificações constitucionais realizadas por meio da interpretação. Revista Eletrônica Direito e Política, Programa de PósGraduação Stricto Sensu em Ciência Jurídica da UNIVALI, Itajaí, v.10, n.4, 30 quadrimestre de 2015. Disponível em: www.univali.br/direitoepolitica - ISSN 1980-7791.

é a própria sobrevivência do controle difuso e os efeitos que dele devem ser retirados. ${ }^{20}$

É possível aqui se vislumbrar o tamanho do problema, simplesmente há um risco de regras básicas de o sistema ruírem.

\section{A NECESSIDADE DE CONTROLE SOBRE AS MODIFICAÇÕES CONSTITUCIONAIS DIFUSAS ILEGÍTIMAS}

Uma constituição rígida exige um sistema de controle para the garantir o respeito e a harmonia do sistema, por isso o ordenamento jurídico não suporta normas e atos contrários à sua norma fundamental, seja em razão de uma direta ou indireta incompatibilidade.

Não é só as normas/atos infraconstitucionais que sofrem este controle, posto que existe um núcleo rígido da constituição que não pode ser alterado nem mesmo por emendas constitucionais. Aliás, a Carta Magma proíbe a mera deliberação destas emendas, conforme prevê o art. 60, $\S 40^{21}$.

Existem, outrossim, outros limites à atuação do Poder Legislativo na reforma constitucional, qual seja, 0 art. $60, \S 1^{\circ}$, pelo qual "a Constituição não poderá ser emendada na vigência de intervenção federal, de estado de defesa ou de estado de sítio".

Se o Poder Legislativo, que exerce, como representante do titular do poder constituinte, o povo, por expressa disposição constitucional, a função de constituinte derivado, possui limitações para a reforma constitucional, não pode

20 STRECK, Lenio Luiz; OLIVEIRA, Marcelo Andrade Cattoni de et al. A nova perspectiva do Supremo Tribunal Federal sobre o controle difuso: mutação constitucional e limites da legitimidade da jurisdição constitucional, p. 7

$21 \S 40$ - Não será objeto de deliberação a proposta de emenda tendente a abolir: I - a forma federativa de Estado; II - o voto direto, secreto, universal e periódico; III - a separação dos Poderes; IV - os direitos e garantias individuais. 
NOGUEIRA, Alexandre de Castro. A mutação constitucional como instrumento do stf para atuar como legislador positivo: a necessidade de um controle externo às modificações constitucionais realizadas por meio da interpretação. Revista Eletrônica Direito e Política, Programa de PósGraduação Stricto Sensu em Ciência Jurídica da UNIVALI, Itajaí, v.10, n.4, 30 quadrimestre de 2015. Disponível em: www.univali.br/direitoepolitica - ISSN 1980-7791.

o Poder Judiciário pretender exercer o poder de reforma difusa (mutação constitucional) sem qualquer limite.

Concluindo da mesma forma, Barroso ${ }^{22}$ que a mutação pode ser concebida até um determinado limite, passada muito das fronteiras aceitáveis passa a serem consideradas inconstitucionais, devendo ser resolvida por meio de sua inibição ou de sua positivação.

Streck, Oliveira e $\operatorname{Lima}^{23}$ assinalam que:

Em determinadas situações, mutação constitucional pode significar, equivocadamente, a substituição do poder constituinte pelo Poder Judiciário. E, com isso, soçobra a democracia. E este nos parece ser o ponto principal da discussão acerca dos votos proferidos na aludida Reclamação 4335-5.

O conceito de mutação constitucional, mostra apenas a incapacidade do positivismo legalista da velha Staatsrechtslehre do Reich alemão de 1870 em lidar construtivamente com a profundidade de sua própria crise paradigmática. E não nos parece que esse fenômeno possui similaridade no Brasil. E mesmo em Hsü-Dau-Lin (referido pelo Ministro Eros Grau) e sua classificação "quadripartite" do fenômeno da mutação constitucional não leva em conta aquilo que é central para o pós-segunda guerra e em especial para a construção do Estado Democrático de Direito na atualidade. A tese da mutação constitucional advoga em última análise uma concepção decisionista da jurisdição e contribui para a compreensão das cortes constitucionais como poderes constituintes permanentes. Ora, um tribunal não pode mudar a constituição; um tribunal não pode "inventar" o direito.

22 BARROSO, Luís Roberto. Curso de direito constitucional contemporâneo: os conceitos fundamentais e a construção do novo modelo. São Paulo: Saraiva, 2011, p. 143

23 STRECK, Lenio Luiz; OLIVEIRA, Marcelo Andrade Cattoni de et al. A nova perspectiva do Supremo Tribunal Federal sobre o controle difuso: mutação constitucional e limites da legitimidade da jurisdição constitucional, p. 19. 
NOGUEIRA, Alexandre de Castro. A mutação constitucional como instrumento do stf para atuar como legislador positivo: a necessidade de um controle externo às modificações constitucionais realizadas por meio da interpretação. Revista Eletrônica Direito e Política, Programa de PósGraduação Stricto Sensu em Ciência Jurídica da UNIVALI, Itajaí, v.10, n.4, $3^{\circ}$ quadrimestre de 2015. Disponível em: www.univali.br/direitoepolitica - ISSN 1980-7791.

Ora, o Poder Judiciário é um poder constituído, como o Legislativo e o Executivo, podendo, excepcionalmente funcionar como legislador negativo, para retirar do mundo jurídico norma ou ato normativo incompatível com a Constituição. Pode, através da interpretação, reconhecer a mutação constitucional, que significa uma alteração semântica de certo termo ou termos expressos na Constituição Federal.

Como Poder constituído que é também se submete aos limites constitucionais em sua atuação, sejam naquelas de competência típica, sejam naqueles de competência atípica, sob pena de se negar um dos fundamentos (talvez o principal) de uma constituição, qual seja, a limitação dos poderes estatais.

Não existe no ordenamento jurídico pátrio instância, no poder Judiciário, acima do STF, da mesma forma que não existe instância superior ao Presidente da República no Poder Executivo e ao Congresso Nacional, no âmbito do Poder Legislativo, mas nenhum deles estão autorizados à descumprir a constituição federal no exercício de suas competências típicas e atípicas.

A partir do momento que o Poder Judiciário ultrapassa os limites de sua competência, ele ofende a Constituição e tem que ser contido. Acontece que, como se verificou pelo julgados retro, o STF tem imposto a alteração do texto constitucional camuflada de mutação. Não há alteração de sentido, mas do próprio texto legal, acréscimo inclusive de palavras.

Verifica-se, dentro dos votos dos ministros (mormente aquelas da reclamação 4335-5), artifícios meramente retóricos e vazios de fundamentos constitucionais (adequados) para a conclusão pela existência de mutação constitucional no sentido (na verdade modificação de texto como se verifica).

A mutação constitucional, por ser um processo difuso, decorrente de meios interpretativos, acaba existindo sem um controle, um impedimento expresso, mormente quando ocorre por decisão do STF.

A Constituição não prevê o controle dos atos judiciais no exercício da jurisdição por nenhum outro poder, posto que a jurisdição gera atos imutáveis, não 
NOGUEIRA, Alexandre de Castro. A mutação constitucional como instrumento do stf para atuar como legislador positivo: a necessidade de um controle externo às modificações constitucionais realizadas por meio da interpretação. Revista Eletrônica Direito e Política, Programa de PósGraduação Stricto Sensu em Ciência Jurídica da UNIVALI, Itajaí, v.10, n.4, $3^{\circ}$ quadrimestre de 2015. Disponível em: www.univali.br/direitoepolitica - ISSN 1980-7791.

podendo ser revistos fora dos casos expressos no sistema pelo próprio Poder Judiciário, conforme está previsto no art. 50, XXXVI ("a lei não prejudicará o direito adquirido, o ato jurídico perfeito e a coisa julgada").

Desta forma é tão difícil reconhecer um instrumento de controle contra ao abuso do Judiciário quando esse extrapola a aplicação da reforma difusa da constituição.

Em sede de controle concreto de constitucionalidade, a Constituição Federal no art. 52, X, ainda prevê que caberia ao Senado suspender os efeitos da norma declarada inconstitucional, de forma que, caso não entendesse que fosse devido não determinaria tal suspensão, funcionando como um início, um rascunho de controle contra a reforma por meio difuso da Constituição.

Mas o STF, retirando o último recurso expresso de controle de suas decisões, impôs diretamente a modificação do texto constitucional, para que suas decisões em controle concreto tivesse efeito vinculante e abstrato, independente de qualquer ato do Senado, que seria um mero divulgador, responsável pela publicação das decisões do STF, reduzindo o Senado da República a mera Secretaria do Judiciário, como já afirmou Streck, Oliveira e Lima ${ }^{24}$.

Mas uma solução possível se verifica dentro do ordenamento jurídico pátrio para que os outros Poderes, também representantes do povo, também representantes do Estado Democrático de Direito, possam exercer um controle contra a mutação constitucional reconhecida pelo STF, seja ela legítima ou não: o exercício da proposição e a aprovação de Emendas Constitucionais que repitam o texto constitucional atingido pela "mutação".

O texto constitucional permanece o mesmo quando o Poder Judiciário Ihe reconhece a mudança pelo meio difuso, mas a alteração constitucional é

\footnotetext{
24 STRECK, Lenio Luiz; OLIVEIRA, Marcelo Andrade Cattoni de et al. A nova perspectiva do Supremo Tribunal Federal sobre o controle difuso: mutação constitucional e limites da legitimidade da jurisdição constitucional, p. 20
} 
NOGUEIRA, Alexandre de Castro. A mutação constitucional como instrumento do stf para atuar como legislador positivo: a necessidade de um controle externo às modificações constitucionais realizadas por meio da interpretação. Revista Eletrônica Direito e Política, Programa de PósGraduação Stricto Sensu em Ciência Jurídica da UNIVALI, Itajaí, v.10, n.4, $3^{\circ}$ quadrimestre de 2015. Disponível em: www.univali.br/direitoepolitica - ISSN 1980-7791.

inegável, mormente quando aquele camufla, na verdade, o exercício ilegítimo de um poder legislativo positivo usurpador.

Dessa forma, o Poder Executivo, através da competência para propor emenda constitucional, e o Legislativo, através desta mesma competência e no exercício da deliberação legislativa, obedecendo às normas constitucionais, poderá, como representantes do povo, exercendo o poder constituinte derivado, trazer de volta aquela norma constitucional modificada pela "mutação constitucional", seja comprovando que não houve necessariamente a mutação, seja demonstrando que a vontade popular que represente deseja ou desejou o retorno da norma modificada, da mesma forma que se emenda a Constituição para reformar normas trazidas por uma emenda anterior que não se mostrou satisfatória para o Estado Democrático de Direito.

\section{CONSIDERAÇÕES FINAIS}

A mutação constitucional como parte do processo evolutivo do ordenamento jurídico, intitulado de modificação difusa da constituição, possui seus limites e fundamentos definidos.

Está fundamentado na teoria de Hesse, posto que a sociedade e a Constituição interagem, uma influindo, às vezes impondo e condicionando a outra, posto que não é mero pedaço de papel e nem a sociedade perde sua dinâmica quando disciplinada juridicamente.

Como fundamento, está a necessidade de evolução e a modificação de sentidos de termos jurídicos e extrajurídicos previsto na Carta, que não podem ficar engessados, na visão antiquada do Poder Constituinte Originário.

A própria vigência da Constituição depende, em certo grau, das modificações a elas necessariamente introduzidas, para adaptá-las à realidade em que está sendo aplicada, no entanto, o Poder competente às vezes não consegue alcançar 
NOGUEIRA, Alexandre de Castro. A mutação constitucional como instrumento do stf para atuar como legislador positivo: a necessidade de um controle externo às modificações constitucionais realizadas por meio da interpretação. Revista Eletrônica Direito e Política, Programa de PósGraduação Stricto Sensu em Ciência Jurídica da UNIVALI, Itajaí, v.10, n.4, $3^{\circ}$ quadrimestre de 2015. Disponível em: www.univali.br/direitoepolitica - ISSN 1980-7791.

essa dinâmica, ignora tal avanço, ou até mesmo vai em sentido oposto ao que deveria ir no que tange ao reconhecimento da adaptação do texto constitucional à realidade vivida pela sociedade.

Nesses casos, quando, por um meio interpretativo, se busca atualizar o sentido da Constituição, há uma legitima mutação constitucional, que não permite ao juiz substituir-se ao legislador constituinte, mas apenas interpretar/aplicar a norma constitucional dentro do seu contexto, afinal existem limite eu devem ser respeitados.

Assim, a supressão o acréscimo de palavras, frases ou mesmo contrariar exatamente a expressão da norma interpretada não é mutação constitucional, mas verdadeira emenda constitucional disfarçada, uma criação constitucional, ou um pan-constitucionalismo.

É o que vem ocorrendo no âmbito do STF, conforme os casos apresentados nesse estudo, dos quais, se colocou, por este trabalho entender como mais graves, não pelo resultado prático, mas pela ofensa à ordem Constitucional, à divisão de competências e à legitima vontade do titular do poder constituinte (art. 10, parágrafo único), mas pelo precedente, que acaba inspirando outras decisões igualmente ofensivas à Constituição: Reclamação 4335-5 e a ADI 4277.

Aconteceu, na solução das respectivas ações, uma interpretação contra constituição e não conforme ela ou de acordo com uma mutação constitucional. Trata-se de inovação, transformação criativa, uma verdadeira emenda constitucional disfarçada, que revoga o texto expresso da norma superior e lhe atribui outras palavras (texto e não sentido).

O ordenamento jurídico deve apresentar uma solução quanto à esse desvio inquestionável de competência, de "poder", devendo os próprios poderes se organizarem e impedir esses "avanços" que mais parecem "conquistas bélicas" que não gozam da simpatia e nem da aceitação do público e principalmente do sistema jurídico constitucional contemporâneo. 
NOGUEIRA, Alexandre de Castro. A mutação constitucional como instrumento do stf para atuar como legislador positivo: a necessidade de um controle externo às modificações constitucionais realizadas por meio da interpretação. Revista Eletrônica Direito e Política, Programa de PósGraduação Stricto Sensu em Ciência Jurídica da UNIVALI, Itajaí, v.10, n.4, 30 quadrimestre de 2015. Disponível em: www.univali.br/direitoepolitica - ISSN 1980-7791.

Por isso se observa, como solução, a atuação do Legislativo, sozinho ou em conjunto com o Executivo propondo (ambos) e aprovando (aquele) emendas constitucionais que repitam o exato texto constitucional violado, demonstrando, assim, o povo, através de seus representantes, ou seja, que o Estado, no exercício de sua competência legislativa, afirma expressamente o seu entendimento pela manutenção do texto constitucional violado, pois as mudanças podem e devem aflorar, mas sempre através do meio mais legítimo e democrático, conforme pré-dispõe o próprio texto constitucional e não através da utilização de meios, como o analisado nesse trabalho, que se perfazem nocivos ao sistema jurídico constitucional vigente.

\section{REFERÊNCIAS DAS FONTES CITADAS}

BARROSO, Luís Roberto. Curso de direito constitucional contemporâneo: os conceitos fundamentais e a construção do novo modelo. São Paulo: Saraiva, 2011.

HESSE, Konrad. A força normativa da Constituição. Tradução de Gilmar Ferreira Mendes. Porto Alegre: Sergio Antônio Fabris Editor, 1991.

\section{Elementos de Direito Constitucional da República Federal da}

Alemanha. Tradução de Luís Afonso Heck. Porto Alegre: Sergio Antonio Fabris Editor, 1998.

KELSEN, Hans. Teoria pura do Direito. Tradução de João Baptista Machado. $8^{a}$ Ed. São Paulo: Martins Fontes, 2008.

LEMOS, Tayara Talita, OLIVEIRA, Rafael Tomaz de et al. Mutação constitucional e democracia: uma (des)construção hermenêutica do problema da intervenção do senado em sede de controle difuso da constitucionalidade - Anais do IX Simpósio Nacional de Direito Constitucional da ABDConst, 2010. 
NOGUEIRA, Alexandre de Castro. A mutação constitucional como instrumento do stf para atuar como legislador positivo: a necessidade de um controle externo às modificações constitucionais realizadas por meio da interpretação. Revista Eletrônica Direito e Política, Programa de PósGraduação Stricto Sensu em Ciência Jurídica da UNIVALI, Itajaí, v.10, n.4, $3^{\circ}$ quadrimestre de 2015. Disponível em: www.univali.br/direitoepolitica - ISSN 1980-7791.

Disponível em: <http://abdconst.com.br/revistas_interna3.php>. Acesso em: 20 abr. 2014.

MIRANDA, Jorge. Manual de Direito Constitucional. 6a Ed. 2a ed. Coimbra: Coimbra Editoral, 2007.

STRECK, Lenio Luiz; OLIVEIRA, Marcelo Andrade Cattoni de et al. A nova perspectiva do Supremo Tribunal Federal sobre o controle difuso: mutação constitucional e limites da legitimidade da jurisdição constitucional. Jus Navigandi, Teresina, ano 12, n. 1498, 8 ago. 2007. Disponível em: <http://jus.com.br/artigos/10253>. Acesso em: 25 abr. 2014.

Submetido em: Novembro/2015

Aprovado em: Novembro/2015 